\title{
Comparative study of functional outcomes between OTA/AO type C, Gustilo type I/II open fractures and closed fractures of the distal humerus treated by open reduction and internal fixation
}

Chen Chen, Dan Xiao, Ting Li, Maoqi Gong, Yejun Zha, Kehan Hua, Weitong Sun, Shangwei Ji and Xieyuan Jiang ${ }^{*}$

\begin{abstract}
Background: To evaluate the difference of functional outcomes between OTA/AO type C, Gustilo type I/II open fractures and closed fractures of the distal humerus after open reduction and internal fixation.

Methods: We retrospectively analyzed the clinical data of patients with OTA/AO-C distal humerus fractures who were treated in our department from January 2014 to December 2016. The patients were divided into an open fracture group and a closed fracture group. Their baseline characteristics and functional outcomes were analyzed and compared.
\end{abstract}

Results: A total of 64 patients treated by operative fixation were identified ( 25 open and 39 closed injuries), and the average follow-up time was $35.1 \pm 13.6$ months. There were no significant differences in the range of motion (ROM) of the elbow, Mayo Elbow Performance Score (MEPS), Disabilities of the Arm, Shoulder and Hand (DASH) score, complications, hospitalization time, operation time, intraoperative blood loss, or medical costs between the two groups $(P>0.05)$.

Conclusion: OTA/AO type C, Gustilo I/II distal humeral open fractures can yield satisfactory clinical results similar to those of closed distal humeral fractures after open reduction and internal fixation.

Level of evidence: Therapeutic Level III; Retrospective Cohort Comparison; Treatment Study.

Keywords: Open fracture, Gustilo type I/II, Distal humeral fracture, Open reduction and internal fixation

\section{Background}

The incidence of distal humerus fractures is approximately 5.7 cases per 100,000 per year $[1,2]$. Most adult distal humerus fractures (96\%) are OTA/AO-C fractures, which are often resulted from high-energy trauma [3].

*Correspondence: jxy0845@sina.com

Department of Orthopedic Trauma, Beijing Jishuitan Hospital, No.31

Xinjiekou East Street, Xicheng District, Beijing 100035, China
This type of fracture was difficult to treat due to comminuted articular surface and poor soft tissue conditions [4]. With the advancement of surgical technique in recent years, many studies have shown that open reduction and internal fixation (ORIF) can yield good outcomes in distal humerus fractures [5-9].

However, open distal humerus fractures are still a great challenge for orthopedic surgeons to manage owing to its fracture fragments penetrating the soft tissue of the original author(s) and the source, provide a link to the Creative Commons licence, and indicate if changes were made. The images or other third party material in this article are included in the article's Creative Commons licence, unless indicated otherwise in a credit line to the material. If material is not included in the article's Creative Commons licence and your intended use is not permitted by statutory regulation or exceeds the permitted use, you will need to obtain permission directly from the copyright holder. To view a copy of this licence, visit http://creativecommons.org/licenses/by/4.0/. The Creative Commons Public Domain Dedication waiver (http://creativeco mmons.org/publicdomain/zero/1.0/) applies to the data made available in this article, unless otherwise stated in a credit line to the data. 
elbow, which leads to severe soft tissue injury and often result in deep infection, fracture nonunion, and elbow stiffness [10]. The Gustilo-Anderson classification system is universally used for open fractures [11]. Gustilo type I/ II fractures are low-energy injuries, with minimal soft tissue injuries, and type III fractures are high-energy injuries that are often accompanied by extensive soft tissue injuries $[12,13]$.

Most of the existing studies focused on open distal humerus fracture treatments alone, without further evaluating the subtypes of Gustilo classes [5, 14]. The treatment methods for type I/II and type III fractures are different. Type III fractures are often treated with a staged procedure, with external fixation as the primary surgery and ORIF or external fixation as the definitive treatment [15-17]. In contrast, type I/II fractures can be treated with debridement and ORIF in a one-stage manner $[4,18-20]$ with good results as suggested by McKee et al. [5] However, there were no studies comparing the difference of functional outcomes between OTA/AO type C, Gustilo type I/II, distal humerus open fractures and closed fractures treated by ORIF. Therefore, in this article, we reviewed Gustilo I and II, type C open fractures and closed fractures of the distal humerus treated in our hospital from 2014 to 2016 and compares the functional outcomes of the two groups treated by ORIF.

\section{Methods}

\section{Patients}

This was a retrospective, cohort, single-center study performed in our hospital. We obtained institutional review board approval for this retrospective investigation, and informed consent was obtained from each patient. The inclusion criteria were as follows: (1) patients with OTA/
AO-C open and closed distal humerus fractures who were treated using ORIF from January 2014 to December 2016; (2) aged 18 years or older; and (3) follow-up period more than 2 year. The exclusion criteria were patients with (1) Gustilo type III open fractures; (2) pathological fractures; or (3) combined with other injuries.

All of the patients were examined in emergency to identify whether there were combined injuries and underwent radiographic imaging scans (anterior-posterior, lateral X-rays and CT scans) of the elbow to confirm the diagnosis and classification. Physical examinations were performed to determine whether there were neurovascular injuries. Patients with open fractures were treated with tetanus prophylaxis and antibiotics (cephalosporin or clindamycin, until the third day after ORIF) [21] and were immediately moved to the operating room for irrigation, debridement, and either immediate fixation or secondary fixation, depending on the condition of the patient's soft tissue and doctor's experiences (Fig. 1). For the patients who were treated by secondary fixation, the wounds were sutured, the elbows were immobilized using arm braces, and the wound dressings were changed daily for wound observing. If the wounds did not have swelling, erythema or drainage, the patients underwent ORIF 10-14 days later.

\section{Surgical technique}

In ORIF surgery, the patients were anesthetized with brachial plexus block and operated through the posterior approach. After the skin was incised, the full-thickness flap was lifted, and the ulnar nerve was exposed and protected during the operation. If the joint needed to be fully exposed, olecranon osteotomy was performed. If the fracture could be directly reduced, the paratricipital

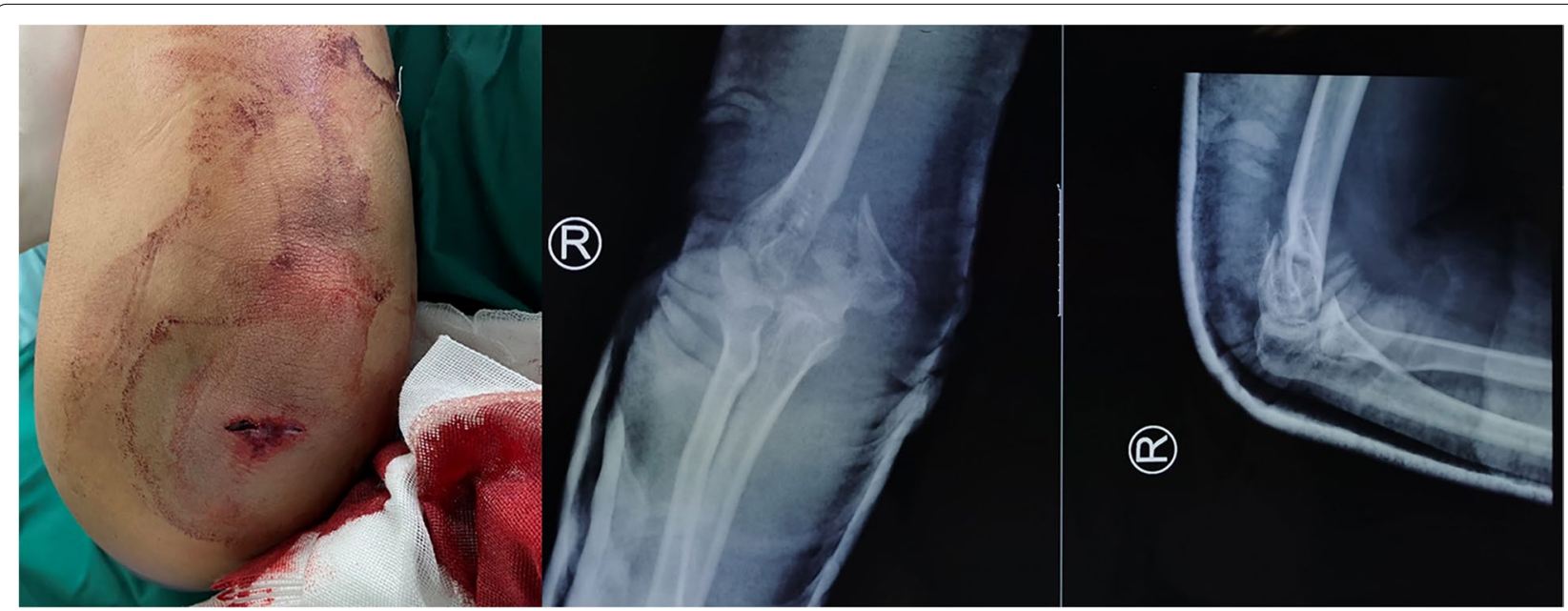

Fig. 1 OTA/AO type C, Gustilo type I open fracture 
approach involving both sides of the triceps was used. Reduction forceps and K-wires were used to maintain the reduction, then 2 anatomical locking plates and screws were used for fracture fixation. The plates were placed in parallel or vertically according to the surgeon's preference [22]. After reduction and fixation were achieved, the ulnar nerve was transposed anteriorly to ensure that it was separated from the implant. The fascia and subcutaneous tissue were closed layer by layer, and the incision was closed after drainage. All of the patients were intravenously infused with second-generation cephalosporin antibiotics from $30 \mathrm{~min}$ before the internal fixation to 2 days after surgery.

\section{Postoperative treatment}

All of the patients started elbow rehabilitation on the second postoperative day. After the operation, the patients were followed up by a review clinic, and radiographs of the elbow were taken. The last follow-up was performed more than 2 year postoperatively (Fig. 2 ). In the last follow-up, we measured the ROM of the elbow, which is the primary outcome of the study. The secondary outcomes include: the Mayo Elbow Performance Score (MEPS), which was used to objectively evaluate the elbow with regard to 4 aspects: pain (45 points), range of motion (20 points), stability (10 points), and the ability to perform activities of daily living (25 points) [23]. The Disabilities of the Arm, Shoulder and Hand (DASH) questionnaire, which was used to subjectively evaluate elbow-related symptoms and disability $[1,24]$. Complications such as infection, fracture nonunion, ulnar nerve symptoms, elbow stiffness, local irritation of the implant and secondary operations were recorded. Ulnar nerve injury was defined as a local sensory abnormality or weakened muscle strength after surgery [25]. Elbow stiffness was generally defined as an elbow range of motion (ROM) less than 100 degrees either in flexion-extension or in pronationsupination [26].

\section{Statistical analysis}

Statistical analyses were performed using SPSS software for Windows (IBM SPSS Statistics, version 24; IBM, Armonk, NY, USA). For the quantitative variables, the descriptive statistics included means, medians, standard deviations, and ranges. The normally distributed data were compared using the $t$ test for independent means. If the data were not normally distributed, the Wilcoxon rank-sum test was used. $P<0.05$ was considered statistically significant.

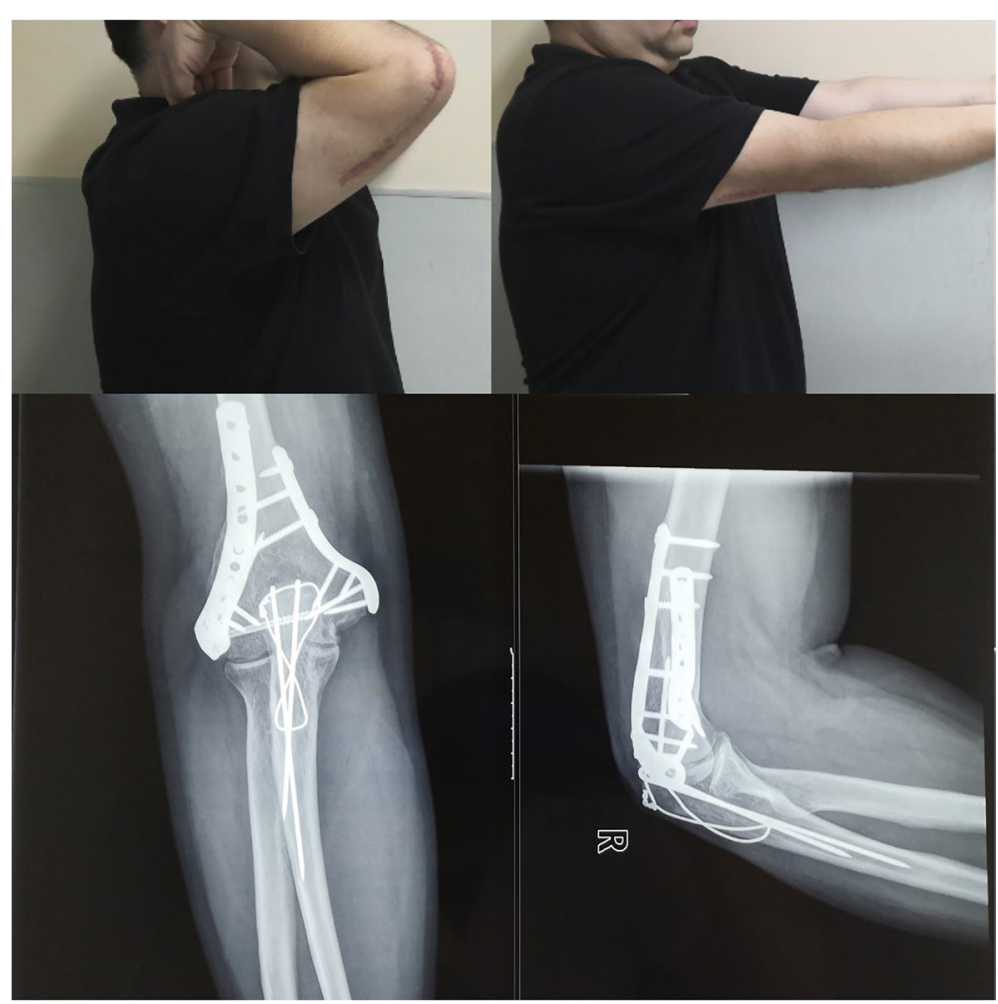

Fig. 2 The elbow function and X-ray at the last follow-up 
Table 1 Comparison of the baseline characteristics between the two groups

\begin{tabular}{lllll}
\hline Baseline characteristic & & Open $(\boldsymbol{n}=\mathbf{2 5})$ & Closed $(\boldsymbol{n}=\mathbf{3 9})$ & $\mathbf{P V a l u e}$ \\
\hline Age[Mean \pm SD] & Male & $43.2 \pm 13.2$ & $39.8 \pm 15.2$ & 0.351 \\
Sex & Female & 18 & 20 & 0.076 \\
Injury energy level & High energy & 7 & 14 & 0.130 \\
& Low energy & 14 & 25 & \\
Injury-to-operation time $[M(P 25$, P75)](days) & 11 & $5.0(3.0,7.0)$ & 0.648 \\
Follow-up period & $6.0(1.0,9.0)$ & $34.7 \pm 8.8$ & 0.696 \\
\hline
\end{tabular}

Table 2 Comparison of the perioperative outcomes between the two groups

\begin{tabular}{llll}
\hline Functional outcome & Open & Closed & P Value \\
\hline hospitalization time (days) & $9.0(6.0,13.0)$ & $8.0(7.0,10.0)$ & 0.220 \\
operation time (minutes) & $165(120,180)$ & $150(120,180)$ & 0.306 \\
intraoperative blood loss (ml) & $100(100,200)$ & $100(100,200)$ & 0.852 \\
treatment cost (Kyuan) & $102(87,120)$ & $93(85106)$ & 0.645 \\
\hline
\end{tabular}

Table 3 Comparison of the functional outcomes between the two groups

\begin{tabular}{|c|c|c|c|c|}
\hline \multicolumn{2}{|c|}{ Functional outcome } & Open & Closed & $P$ Value \\
\hline \multicolumn{2}{|c|}{ ROM of flexion and extension } & $118.9^{\circ} \pm 25.6^{\circ}$ & $121.2 \pm 25.5$ & 0.724 \\
\hline \multicolumn{2}{|l|}{ ROM of rotation } & $150.4^{\circ} \pm 9.9^{\circ}$ & $153.5^{\circ} \pm 9.6^{\circ}$ & 0.227 \\
\hline \multicolumn{2}{|l|}{ MEPS } & $89.2^{\circ} \pm 9.1^{\circ}$ & $89.5^{\circ} \pm 11.1^{\circ}$ & 0.914 \\
\hline \multicolumn{2}{|l|}{ DASH } & $4.2(0.8,9.2)$ & $2.5(0,10.0)$ & 0.530 \\
\hline \multirow[t]{4}{*}{ Compli-cations } & $\begin{array}{l}\text { Ulnar nerve } \\
\text { injury }\end{array}$ & 6 & 9 & 0.932 \\
\hline & Elbow stiffness & 3 & 5 & 0.923 \\
\hline & \multirow{2}{*}{$\begin{array}{l}\text { Local irritability } \\
\text { of Internal } \\
\text { fixation } \\
\text { Nonunion }\end{array}$} & 3 & 2 & 0.318 \\
\hline & & 1 & 1 & 0.747 \\
\hline
\end{tabular}

\section{Result}

The data for 64 patients with type $\mathrm{C}$ distal humerus fractures were collected from our database, and 25 cases were open fractures. The average follow-up duration was $35.1 \pm 13.6$ months(range, 25 to 46 months). The baseline characteristics [age, sex, body mass index (BMI), injury energy level, injury-to-operation time] were analyzed. There were no statistically significant differences between the open and closed fracture groups in the baseline characteristics (age, sex, injury energy level, injury-to-operation time, $\mathrm{P}>0.05)$. (Table 1 ).

The perioperative and functional outcomes are reported in Table 2 and Table 3. The ROM of flexion and extension of open group is $118.9^{\circ} \pm 25.6^{\circ}$, while another group is $121.2^{\circ} \pm 25.5^{\circ}(\mathrm{P}>0.05)$. The $\mathrm{ROM}$ of rotation of the two groups are $\left(150.4^{\circ} \pm 9.9^{\circ}\right)$ and $\left(153.5^{\circ} \pm 9.6^{\circ}\right)$ $(\mathrm{P}>0.05)$. There were no statistically differences in the MEPS, DASH, hospitalization time, operation time, intraoperative blood loss, or treatment cost between the open group and the closed group $(\mathrm{P}>0.05)$. In terms of complications, there were no statistically significant differences in ulnar nerve injuries, elbow stiffness or local irritability in the region of internal fixation $(P>0.05)$. There was one case of nonunion of distal humerus fracture in closed group and one case of nonunion of olecranon osteotomy in open group. There was no patient had an infection.

\section{Discussion}

The incidence of open distal humerus fractures is not high, but the fractures are difficult to treat, and the prognoses are very poor [27]. The fractures are difficult to treat because most of these injuries are caused by highenergy trauma, and the fractures are severely comminuted. In addition, compared with other joints, the elbow is a subcutaneous joint with thin soft tissue coverage and a complicated bone structure. If elbow injuries are not managed properly, patients will develop joint stiffness and other major complications. Even if good soft tissue treatment, anatomical reduction, and early rehabilitation have been achieved after surgery, postoperative upper limb dysfunction and related complications may still occur [28-30].

Chaudhary et al. [10] reported 8 cases of open intraarticular distal humerus fractures that were treated with open reduction and external fixation. The patients were followed up for an average of 11.4 months, they had an average ROM of $20^{\circ}-120^{\circ}$, and 6 patients' functional outcomes were excellent. Kömürcü et al. [31] reported 20 cases of open distal humerus fractures caused by gunshot wounds. The average follow-up duration was 34.3 months. There were 19 cases that were managed with external fixators. Regarding to MEPS, 8 cases had excellent final results, 7 cases had 
good results, and 4 cases had poor results. McKee et al. [5] reviewed 26 patients with open distal humerus fractures who were followed up for an average of 51 months. All the patients were treated with internal fixation after emergency debridement. The final average ROM was $97^{\circ}\left(55^{\circ} \sim 140^{\circ}\right)$, and the MEPS was 79 (52 to 100 ). Complications included 1 case of deep infection and 2 cases of superficial infection. The patient with deep infection had Gustilo type III fractures. Kloen et al. [16] reported 16 cases of open intra-articular distal humeral fractures with temporary joint-spanning external fixation before internal fixation. The patients were followed up for an average of 35.2 months. All fractures united at an average of 5.2 months after internal fixation. No complications specifically related to the external fixation occurred. The DASH outcome score averaged 15.1, and 10 of 16 had an excellent/good outcome score. Min et al. [14] reported 14 patients with AO/OTA type C open distal humeral fractures and 14 closed fractures. For the open group, external fixation or ORIF were performed according to the injury after debridement treatment. For the closed group, ORIF was performed within 5 days after injury. The average follow-up time was $98.9(52-160)$ weeks. The flexion-extension ROM was $108 \pm 28.5^{\circ}$ in the closed group and $82.5 \pm 32.2^{\circ}$ in the open group; the MEPS was $84.6 \pm 19.3$ in the closed group and $67.9 \pm 22.4$ in the open group. These differences between groups were statistically significant $(P<0.05)$.

These studies show that open distal humerus fractures can be treated with open reduction and internal or external fixation, and their prognoses are worse than those of closed fractures. However, previous studies have not considered the Gustilo subtypes. For Gustilo I, II and III fractures, the treatment methods and prognoses are significantly different. At present, the mainstream view is that Gustilo I and II fractures can be fixed in one surgery after debridement [4, 18-20, 32], and whether type III distal humerus fractures can be fixed in one surgery with debridement is still controversial [33-36]. Type III distal humerus fractures are mostly caused by high-energy trauma. The fractures are comminuted and accompanied by soft tissue defects, often requiring damage control surgery and multiple secondary soft tissue reconstruction treatments [37], with external fixation as the primary surgery and open reduction and internal fixation (ORIF) or external fixation as the definitive treatment [15, $16,18]$. Both treatments lead to a prolonged time of immobilization, which will result in functional loss of the involved elbow. In McKee's study, severe complications such as deep infections occurred only in Gustilo III patients, and the author did not discuss type I/II patients separately [5]. Therefore, although this study showed that ORIF can be used to treat open distal humeral fractures, for patients with Gustilo type I and II fractures, whether ORIF can provide the same clinical effect a is not clear.

In summary, the clinical prognosis and risk of complications of Types I/II and III are significantly different, and previous clinical studies did not classify patients by Gustilo classes. Therefore, this study classified patients according to Gustilo classes and compared the treatment outcomes and prognoses of Gustilo I/II open fractures and closed fractures.

A total of 64 cases of type $C$ distal humerus fractures were collected, and 25 cases were open fractures. There were no statistically differences in the ROM, MEPS, DASH score, hospitalization time, operation time, intraoperative blood loss, or treatment cost between the open group and the closed group. In terms of complications, there were no statistically significant differences in the rates for ulnar nerve injuries, elbow stiffness, nonunion or local irritation in the region of internal fixation.

Based on this result, for both AO/OTA type C Gustilo I/II open distal humerus fractures and closed distal humerus fractures, ORIF can be performed with the same approach after thorough debridement. Emergency ORIF can lead to early rehabilitation, so we recommend this procedure if possible in order to prevent elbow stiffness.

The advantage of this study is that it is the first to compare the efficacy of ORIF for AO/OTA Type C Gustilo I/ II open distal humeral fractures and closed distal humeral fractures. However, this study also has some limitations: (1) this study is a retrospective rather than a prospective study, and the method of grouping can bias the results; (2) the Gustilo classification criteria is relatively broad and is determined by the surgeon's judgment intraoperatively; (3) the sample size is larger than those in previous studies, but as open distal humeral fractures are still rare, the sample size is limited, which may have impact the results and statistical power; (4) there were differences between the open group and the closed group in the BMI, which may have impact the results. Therefore, additional large-scale studies are needed.

In summary, AO/OTA type C Gustilo I and II open distal humerus fractures treated with ORIF can exhibit satisfactory clinical results similar to those of closed distal humerus fractures in short terms. There were no significant differences in functional outcomes or complications between the open and closed groups. Moreover, the mean hospitalization time, operation time, intraoperative blood loss and treatment cost did not differ between groups. These results prove that the current treatment for this type of open fracture is reasonable. 


\begin{abstract}
Abbreviations
ORIF: Open reduction and internal fixation; MEPS: The mayo elbow performance score; DASH: The disabilities of the arm, shoulder and hand; ROM: Range of motion; BMI: Body mass index.
\end{abstract}

\section{Acknowledgements}

\section{Not applicable.}

\section{Authors' contributions}

All listed authors made significant contributions to this manuscript. CC and XD wrote the manuscript, CC and ZYJ performed surgeries, LT, GMQ and SWT collected the follow-up data, XD, JSW and HKH performed statistical analysis and data management, JXY initiated the study, JXY, LT, CC were major contributor in the revision of this manuscript. All authors read and approved the final manuscript.

\section{Funding}

1. Funder: Beijing municipal health commission

Grant name (number): Beijing Municipal Health Commission (BMHC2019-9).

2. Funder: Beijing Natural Science Foundation

Grant name (number): Beijing Natural Science Foundation (L192049).

3. Funder: Beijing Jishuitan Hospital

Grant name (number): Beijing Jishuitan Hospital Nova Program(XKXX202103)

\section{Availability of data and materials}

The datasets generated and/or analysed during the current study are not publicly available due to limitations of ethical approval involving the patient data and anonymity but are available from the corresponding author on reasonable request.

\section{Declarations}

\section{Ethics approval and consent to participate}

This study had been approved by Institutional Review Board (IRB) of Beijing Jishuitan Hospital (JST201905-03), and all methods were performed in accordance with the relevant guidelines and regulations. Informed consent was obtained from each patient.

\section{Consent for publication}

We confirmed that the written consent to publish this manuscript was obtained from the study participant.

\section{Competing interests}

The authors declare that they have no competing interests.

Received: 5 August 2021 Accepted: 25 October 2021

Published online: 10 November 2021

\section{References}

1. Robinson CM, Hill RM, Jacobs N, Dall G, Court-Brown CM. Adult distal humeral metaphyseal fractures: epidemiology and results of treatment. J Orthop Trauma. 2003;17(1):38-47.

2. Rose SH, Melton LJ 3rd, Morrey BF, Ilstrup DM, Riggs BL. Epidemiologic features of humeral fractures. Clin Orthop Relat Res. 1982;168:24-30.

3. Pollock JW, Faber KJ, Athwal GS. Distal humerus fractures. Orthop Clin North Am. 2008;39(2):187-200 vi.

4. Kundel K, Braun W, Wieberneit J, Rüter A. Intraarticular distal humerus fractures. Factors affectiong functional outcome. Clin Orthop Relat Res. 1996;332:200-8.

5. McKee MD, Kim J, Kebaish K, Stephen DJ, Kreder HJ, Schemitsch EH. Functional outcome after open supracondylar fractures of the humerus. The effect of the surgical approach. J Bone Joint Surg Br. 2000;82(5):646-51.

6. Jacobson SR, Glisson RR, Urbaniak JR. Comparison of distal humerus fracture fixation: a biomechanical study. J South Orthop Assoc. 1997;6(4):241-9.
7. Sanchez-Sotelo J, Torchia ME, O'Driscoll SW. Complex distal humeral fractures: internal fixation with a principle-based parallel-plate technique. J Bone Joint Surg Am. 2007;89(5):961-9.

8. Theivendran K, Duggan PJ, Deshmukh SC. Surgical treatment of complex distal humeral fractures: functional outcome after internal fixation using precontoured anatomic plates. J Shoulder Elb Surg. 2010;19(4):524-32.

9. Sharma S, John R, Dhillon MS, Kishore K. Surgical approaches for open reduction and internal fixation of intra-articular distal humerus fractures in adults: a systematic review and meta-analysis. Injury. 2018;49(8):1381-91.

10. Chaudhary S, Patil N, Bagaria V, Harshavardhan NS, Hussain N. Open intercondylar fractures of the distal humerus: management using a miniexternal fixator construct. J Shoulder Elb Surg. 2008;17(3):465-70.

11. Gustilo RB, Anderson JT. Prevention of infection in the treatment of one thousand and twenty-five open fractures of long bones: retrospective and prospective analyses. J Bone Joint Surg Am. 1976;58(4):453-8.

12. Meinberg EG, Agel J, Roberts CS, Karam MD, Kellam JF. Fracture and dislocation classification Compendium-2018. J Orthop Trauma. 2018;32(Suppl 1):S1-S170.

13. Ukai T, Hamahashi K, Uchiyama Y, Kobayashi Y, Watanabe M. Retrospective analysis of risk factors for deep infection in lower limb Gustilo-Anderson type III fractures. J Orthop Traumatol. 2020;21(1):10.

14. Min W, Ding BC, Tejwani NC. Comparative functional outcome of AO/ OTA type $C$ distal humerus fractures: open injuries do worse than closed fractures. J Trauma Acute Care Surg. 2012;72(2):E27-32.

15. Nieto H, Baroan C. Limits of internal fixation in long-bone fracture. Orthop Traumatol Surg Res. 2017;103(1S):S61-6.

16. Kloen P, Helfet DL, Lorich DG, Paul O, Brouwer KM, Ring D. Temporary joint-spanning external fixation before internal fixation of open intraarticular distal humeral fractures: a staged protocol. J Shoulder Elb Surg. 2012;21(10):1348-56.

17. Griffin M, Malahias M, Khan W, Hindocha S. Update on the management of open lower limb fractures. Open Orthop J. 2012;6:571-7.

18. Gustilo RB. Current concepts in the management of open fractures. Instr Course Lect. 1987;36:359-66.

19. Min W, Anwar A, Ding BC, Tejwani NC. Open distal humerus fractures-review of the literature. Bull NYU Hosp Jt Dis. 2010;68(4):257-61.

20. Pajarinen J, Björkenheim JM. Operative treatment of type C intercondylar fractures of the distal humerus: results after a mean follow-up of 2 years in a series of 18 patients. J Shoulder Elb Surg. 2002;11(1):48-52.

21. Assunção A, Oliveira de ST. Clínical audit of primary treatment of open fractures: antibiotic treatment and tetanus prophylaxis. Rev Bras Ortop (Sao Paulo) 2020. 55(3): 284-292.

22. Wang X, Liu G. A comparison between perpendicular and parallel plating methods for distal humerus fractures: a meta-analysis of randomized controlled trials. Medicine (Baltimore). 2020;99(23):e19602.

23. Cusick MC, Bonnaig NS, Azar FM, Mauck BM, Smith RA, Throckmorton TW. Accuracy and reliability of the Mayo elbow performance score. J Hand Surg Am. 2014;39(6):1146-50.

24. Hammond A, Prior Y, Tyson S. Linguistic validation, validity and reliability of the British English versions of the disabilities of the arm, shoulder and hand (DASH) questionnaire and QuickDASH in people with rheumatoid arthritis. BMC Musculoskelet Disord. 2018;19(1):118.

25. Calfee RP, Manske PR, Gelberman RH, Van Steyn MO, Steffen J, Goldfarb CA. Clinical assessment of the ulnar nerve at the elbow: reliability of instability testing and the association of hypermobility with clinical symptoms. J Bone Joint Surg Am. 2010;92(17):2801-8.

26. Ranganathan K, Loder S, Agarwal S, et al. Heterotopic ossification: basic-science principles and clinical correlates. J Bone Joint Surg Am. 2015;97(13):1101-11.

27. Lawing CR, Lin FC, Dahners LE. Local injection of aminoglycosides for prophylaxis against infection in open fractures. J Bone Joint Surg Am. 2015;97(22):1844-51.

28. Patzakis MJ, Wilkins J. Factors influencing infection rate in open fracture wounds. Clin Orthop Relat Res. 1989;243:36-40.

29. Wiggers JK, Brouwer KM, Helmerhorst GT, Ring D. Predictors of diagnosis of ulnar neuropathy after surgically treated distal humerus fractures. J Hand Surg Am. 2012;37(6):1168-72.

30. Frattini M, Soncini G, Corradi M, Panno B, Tocco S, Pogliacomi F. Midterm results of complex distal humeral fractures. Musculoskelet Surg. 2011;95(3):205-13. 
31. Kömürcü M, Yanmiş I, Ateşalp AS, Gür E. Treatment results for open comminuted distal humerus intra-articuler fractures with Ilizarov circular external fixator. Mil Med. 2003;168(9):694-7.

32. Suzuki T, Hak DJ, Stahel PF, Morgan SJ, Smith WR. Safety and efficacy of conversion from external fixation to plate fixation in humeral shaft fractures. J Orthop Trauma. 2010;24(7):414-9.

33. Mathews JA, Ward J, Chapman TW, Khan UM, Kelly MB. Single-stage orthoplastic reconstruction of Gustilo-Anderson grade III open tibia fractures greatly reduces infection rates. Injury. 2015:46(11):2263-6.

34. Bach AW, Hansen ST Jr. Plates versus external fixation in severe open tibial shaft fractures. A randomized trial. Clin Orthop Relat Res. 1989:241:89-94.

35. Mundi R, Chaudhry H, Niroopan G, Petrisor B, Bhandari M. Open tibial fractures: updated guidelines for management. JBJS Rev. 2015;3(2):e1-e1.
36. Singh J, Dhillon MS, Dhatt SS. Single-stage "fix and flap" gives good outcomes in grade 3B/C open Tibial fractures: a prospective study. Malays Orthop J. 2020;14(1):61-73.

37. Roberts CS, Pape HC, Jones AL, Malkani AL, Rodriguez JL, Giannoudis PV. Damage control orthopaedics: evolving concepts in the treatment of patients who have sustained orthopaedic trauma. Instr Course Lect. 2005;54:447-62.

\section{Publisher's Note}

Springer Nature remains neutral with regard to jurisdictional claims in published maps and institutional affiliations.
Ready to submit your research? Choose BMC and benefit from:

- fast, convenient online submission

- thorough peer review by experienced researchers in your field

- rapid publication on acceptance

- support for research data, including large and complex data types

- gold Open Access which fosters wider collaboration and increased citations

- maximum visibility for your research: over $100 \mathrm{M}$ website views per year

At BMC, research is always in progress.

Learn more biomedcentral.com/submissions 